\title{
Women's Awareness and Attitudes towards Labor Analgesia Influencing Practice between Developed and Developing Countries
}

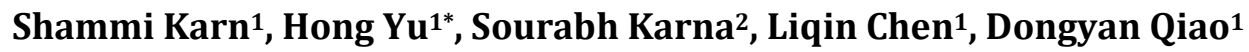 \\ ${ }^{1}$ Department of Obstetrics and Gynecology, Zhong Da Hospital, Medical School, Southeast University, Nanjing, \\ China \\ ${ }^{2}$ Nepal Medical College, Kathmandu University, Kathmandu, Nepal \\ Email: *yuhong650325@sina.com
}

Received 4 March 2016; accepted 6 May 2016; published 9 May 2016

Copyright (C) 2016 by authors and Scientific Research Publishing Inc.

This work is licensed under the Creative Commons Attribution International License (CC BY). http://creativecommons.org/licenses/by/4.0/

(c) (i) Open Access

\begin{abstract}
Childbirth experience is one of the most intense pain that majority of women will endure during their lifetime. Concerns about pain in labor remain a hot topic, and its popularity gets more common day by day as more women become aware of their rights to achieve a better quality of care during labor. There are various non-pharmacologic (transcutaneous electrical nerve stimulation, hydrotherapy, intradermal water injections and acupuncture) and pharmacologic treatments (nitrous oxide, opioids and regional analgesia techniques: spinal, epidural and combined epidural analgesia) available today. Among these, epidural analgesia offers the most effective form of pain relief and is considered to be the gold standard of labor analgesia. Despite having labor analgesic services, most women still go through painful labor due to lack of knowledge regarding it, particularly in developing countries. The main source of information regarding pain reliefs is from friends and relatives, revealing the lack of information from caregiver's side. So this study reflects that there is a wide gap in the communication between pregnant women and obstetricians. It supports the fact that obstetricians through the practice of routinely offering labor analgesia can significantly improve the maternal and perinatal outcomes of pregnancy. Provision of standardized epidural analgesia information at an appropriate time in their pregnancy may benefit them by the practice of mutual decision-making. Thus, it may prevent women from making a difficult choice of cesarean section to avoid the fear of painful labor.
\end{abstract}

\section{Keywords}

Pain Relief, Epidural Analgesia, Labor Analgesia, Developing Country, Developed Country,

*Corresponding author.

How to cite this paper: Karn, S., Yu, H., Karna, S., Chen, L.Q. and Qiao, D.Y. (2016) Women's Awareness and Attitudes towards Labor Analgesia Influencing Practice between Developed and Developing Countries. Advances in Reproductive Sciences, 4, 46-52. http://dx.doi.org/10.4236/arsci.2016.42007 


\section{Labor Pain}

\section{Introduction}

The pain during labor is a central part of women's experience of childbirth, whose excruciating nature makes most women want to alleviate it. Childbirth is among one of the most intense pain that majority of women will endure during their lifetime [1]-[3]. Concerns about pain in labor remain a hot topic, and its popularity gets more common day by day as more women become aware of their rights to achieve a better quality of care during labor [4]. Normal vaginal delivery for women is a painful event due to frequent uterine contractions, cervical dilatation, stretching of the lower uterine segment and vaginal lacerations [5]. Thus labor pain is one of the major issues women face during the final phase of pregnancy, which can affect all multidimensional aspects of pregnant women's daily life. Unrelieved, labor pain may have a negative impact on the lives of the expectant mother to such an extent that she, including her baby and family members, may also get affected [1]. Although severe pain during labor is not life-threatening for a healthy parturient, it may result in the stimulation of the sympathetic nervous system leading to maternal hypertension, oxygen consumption and adversely affecting uteroplacental blood flow. It may also contribute to psychological consequences like postpartum depression and post-traumatic stress disorder [1] [6]. Many of these effects are mitigated by effective pain relief methods that may benefit the mother and fetus by decreasing maternal hyperventilation and catecholamine secretion [1] [7] [8].

Even for obstetric caregivers, search for the ideal obstetrical analgesic agent continues to be a matter of much interest and research [9]. The American College of Gynecologist and Obstetricians (ACOG) recommends that pain management should be provided whenever medically indicated during labor [10]. Also, the United Kingdom (UK)'s National Institute for Clinical Excellence highly recommends provision of education for expectant mother on the options and availability of effective analgesia services in labor as a means of ensuring that they receive optimal analgesia service during childbirth [1]. Today, there are the wide range of pharmacological and non-pharmacological techniques of pain relief available for women to avoid the pain during labor and has been widely used in recent years [5]-[7] [11].

These pharmacological methods known are nitrous oxide, opioids and regional analgesia techniques: -spinal, epidural and combined epidural analgesia. The non-pharmacological methods include such as breathing exercises, labor support, transcutaneous electrical nerve stimulation, acupuncture, hypnosis, hydrotherapy and sterile water injections [5] [7] [12]. But, overall, epidural anesthesia remained the gold standard and based on the findings of many researchers, it is an ideal labor pain relief method revealing safe and effective service [6].

Epidural Analgesia is a technique of injecting a combination of local anesthetic and opioid analgesic into the lumbar epidural space. This then diffuses into the subarachnoid space where it acts on the spinal nerve roots to block action potential transmission, thus inhibiting perception of pain [8]. Epidural analgesia minimizes the labour pain by decreasing blood catecholamine levels, which in turn significantly increases intervillous blood flow in healthy pregnant women. So, it is the only technique capable of relieving labor pain satisfactorily without maternal or fetal sedation and is the most effective method for restoration of normal uterine activity [8] [13].

However, epidural analgesia has not been still fully accepted and is not routinely practiced in most of the obstetric health centers in developing countries despite many advantages of this technique [13]. The patients do not demand it, and the obstetricians are not keen to routinely practice for several reasons. The core reasons are paucity of qualified anesthesiologist, inadequate analgesic service provision, lack of sophisticated equipments/devices and low parturient demand and awareness [14] [15]. But on the other hand, use of epidural analgesia in labor is widespread in modern labor ward in western countries and its benefits regarding pain relief are wellrecognized. This study was conceived in a background whether the practice of pain relief in labor is evolving and where women are seeking to fulfill their need for pain-free labor. This study aims to highlight the awareness level of pregnant women about labor analgesia and inherent deficiencies in the practical exposure of available epidural analgesic services in the hospitals of low-income countries as compared to western standards. Nevertheless, the preference of pain management modalities during labor can be expected to differ between countries and cultures. 


\section{Discussion}

\subsection{Awareness and Attitudes of Pregnant Women towards Labor Analgesia}

Despite the availability of effective analgesics, still women suffer from the intense pain of labor because of lack of knowledge about the availability of analgesia labor services. Unfortunately, a large population of women has a lack of knowledge about the methods of painless childbirth [5]. It is simply inhumane to let the pregnant women suffer from this intense pain when safe and effective epidural analgesia for painless labor is available. Nevertheless creating awareness by giving proper and full information about epidural analgesia would surely improve the acceptance level among the pregnant women [13]. The results of the study by William WK showed poor general awareness of pregnant women towards the proper role of epidural analgesia in labor, leading to a low patient demand for such services [14]. In his survey, only 994 (47\%) of antenatal patients reported having been exposed to the concept of epidural analgesia in labor. This study also revealed that the leading cause of a low patient demand for epidural analgesia in labor is poor general awareness of pregnant women about the proper role of epidural analgesia and lack of adequate resources to meet the demand. The study by Minhas, M. R. et al. found the awareness of epidural analgesia in the majority of the pregnant women. However, only a small proportion was availing this service, due to fears and misconceptions [15]. Also, a study in the Indian pregnant women showed that majority of mothers still suffer from the agony of labor pain because of lack of awareness, unbound fears and lack of knowledge about the availability of the analgesia service [13].

Similarly, another study in the Indian women by Barakzai, A. et al. found that there is poor general awareness of women about the proper role of epidural analgesia during labor, which makes a low patient demand for such analgesic services [16]. That study also showed that less than half of the women were aware of labor pain relief methods, among them only 12 (9.1\%) had knowledge about epidural analgesia. The women's upbringing, religion, and culture largely influence the attitude towards the pain relief in labor. In the countries of 3rd world, access to knowledge and the availability of obstetric analgesic unit can influence attitudes towards labor pain relief. The results of Barakzai, A. et al. study were comparable to the study conducted in Nigeria, whose findings showed that out of 1000 respondents, only 271 were aware that labor pain could be reduced [9]. Of those, $80 \%$ of the women had an awareness of labor analgesia about the opioids, but only $10 \%$ and $14 \%$ of them were aware of epidural and inhalation analgesic respectively. The descriptive study by James, J., et al. revealed that there is sufficient awareness that labor is painful, and there are agents to relieve pain during labor. However, there is a lack of knowledge about the need for labor pain relief, the various types of pain relief methods along with advantages and disadvantages. Antenatal women should be educated about the need and benefit of pain relief and the available service. It may be done at an appropriate time by the obstetrician during the antenatal visits. The knowledge of pregnant women may also be improved by the provision of information leaflets, manuals, websites and childbirth preparation classes [7].

\subsection{Major Source of Information about Labor Analgesia}

The majority of general source of knowledge about pain relief methods in the Indian women were 76, (58.0\%) from relatives and from their past delivery were 23 (17.5\%) [16]. In the study by Mugambe J. M. et al., most of the women from South Africa also had gained knowledge about pain relief from past experience or from friends and relatives [17]. Also in the several studies, there were similar results of the major source of information that being from their friends and relatives [5] [14]. However the study by Shidhaye R.V. et al. stated that neighbors, relatives and friends cannot be a source of information as they themselves may not have appropriate knowledge. A reliable source of information must be midwives, obstetricians and anesthesiologists who are the base of health service providers [13]. On the other hand, the study done in the population of Northern Nigeria showed the majority of women have heard of pain relief in labor mostly from their caregivers and during the current pregnancy [4]. The high level of awareness in that study could be attributed to increasing discussions on the topic during antenatal visits in that hospital. Thus, encouraging the participation of labor unit nurse to provide obstetrical analgesia as mentioned in ACOG guidelines will greatly expand the capacity and availability of analgesic facilities for the desiring mothers [10]. The study by Atiya Barakzai et al. highly recommends that information leaflets as a source of knowledge regarding epidural analgesia for labor can be applied and distributed among pregnant women during antenatal checkups [16]. Also collaborative approach between obstetrician and anesthetists for the better obstetric analgesic service is important where the appropriate knowledge of epidural 
analgesia will be helpful. The high level of awareness of caregivers in the study and their positive attitude towards the provision of pain relief services provides an opportunity to introduce a systematic way of obstetrical analgesic facilities [6]. It supports the fact that obstetricians through the practice of regularly based labor analgesic service can significantly improve the maternal and perinatal outcomes of pregnancy.

\subsection{Practice of Epidural Analgesia in Developing Countries}

Although epidural analgesia practice has rapidly gained popularity in the developed countries, low usage in the developing world has raised concern [9]. In the third world, especially in Africa, access to knowledge and the availability of labor analgesic care service can influence attitudes to labor analgesia. Majority of women may not have any idea that pain can be relieved. Here, the majority of deliveries mostly occurs at home and is largely attended by unskilled providers. There are women who deliver at home rarely benefit from any means of pain relief agents because of strong belief grounded in their culture, ethics and religion that pain is obviously acceptable during labor. Therefore, it is recommended that any plan to introduce pain relief services should be done through mobilization and education of the community. Thus this will provide them knowledge about the advantages of pain relief in labor [6]. The study by Ogboli N. et al. also further supports same results that majority of women deliver at home without using any means of pain relief agents. Even the women who deliver within the hospital may have little or no knowledge of information and services regarding pain relief methods [4]. In Pakistan epidural analgesia is a new concept, only available in few hospitals, though refusal rate is high for information on epidural analgesic service being provided to pregnant women [15].

\subsection{Practice of Epidural Analgesia in Developed Countries}

Research in western countries has assessed the information and knowledge of the midwives and obstetricians regarding epidural analgesia [18]. In the UK, the non-regional methods are employed more often, while in the United States of America (USA), regional analgesia is the most frequently in service, with the uptake of epidural analgesia as high as $60 \%$ as documented in the study by Nice Clinical Guidelines [19]. Over the past 40 years in the USA, the use of epidural analgesia for childbirth has increased dramatically. The survey conducted in the USA in 2001, reported that over $60 \%$ of women in large maternity hospitals received epidural analgesia during labor [20]. At the Prentice Women's Hospital in Chicago, 90\% of expecting women receive epidural analgesia during labor. The UK’s National Health Service Maternity Statistics of 2005-2006 year reported that one-third of expecting mothers chose epidural analgesia during childbirth [21]. The findings of the study from Israel show a highly significant rise in the preference towards use of epidural analgesia in parturient, concomitant with an increase in their use of epidural analgesia in the previous deliveries [12]. The survey done in France by Balghiti et al. documented $82 \%$ of acceptance rate regarding epidural analgesia with $93 \%$ of satisfaction with the outcome of analgesic effect. In addition, an overwhelming 98\% said they would ask for epidural analgesia in subsequent deliveries [22]. The study by Paech and Gurrin also had similar supportive result among the Australian women who had received epidural analgesia found to have generally high satisfaction [23]. In most of the countries, it is the preferred analgesic technique for labor. In a survey done in the UK, almost $90 \%$ of obstetric units offer 24-hour epidural analgesic service with a high level of acceptance [24]. This is mainly possible by a collaborative approach between anaesthetist, obstetricians, and midwives for providing information regarding epidural analgesia to pregnant women. The survey done by Stamer U. M. et al. in the Germany also documents that there is an improvement of epidural analgesia practice during the last two decades with almost $90 \%$ of the obstetric departments offer epidural analgesia to their pregnant mothers [25].

Accounts from the medical literature report the use of epidural analgesia in the public hospitals of Hong Kong was significantly lower than the rate documented in the West countries like UK where the average epidural rate was $19.7 \%$ and $78 \%$ of obstetrics units offered a $24-h$ service, with $37 \%$ in increasing rates [26] and $26 \%$ of Australian antenatal women were planning to receive epidural analgesia [27]. On the other hand, the rate of epidural analgesia could be as high as $80 \%$ at a private maternity hospital in Hong Kong [28]. These major differences in rates have been explained by findings in other countries as a lack of resources rather than lack of expertise [28] [29]. William WK study further confirms all possibilities for significant contributory factors as a lack of awareness and low demand by pregnant women [14].

It is however, noteworthy that even among expectant mothers in developing countries like Nigeria; epidural analgesia is beginning to gain popularity from the recent researches. These findings suggest that efforts to pro- 
mote the use of epidural analgesia for pain relief in labor could be rewarded swiftly in terms of acceptability by both caregivers and parturient alike [6]. Study by E. R. Horowitz et al. also have similar results of epidural analgesia being more popular, while opioids use lost popularity, confirming that change in attitudes towards pain relief in labor over the last 6 years among the pregnant women of Israel [12].

\subsection{Increase in Cesarean Section (CS) Rate}

Fear of childbirth (FOC) is a serious issue for an expectant mother, thus it leads to an increase rate of maternal requests for CS, avoidance of pregnancy, with maternal and fetal stress [30]. Which leads women to change their preferred mode of delivery due to fear of labor pain and this is one of the most important reasons for the increase rate of elective cesarean section (ELCS) in recent years [31] [32]. The analysis done by Aksoy, M. et al. reported that $66.5 \%$ of women requested for CS due to fear from labor pain [5]. Thus featuring fear of labor pain was found to be one of the major causes for Turkish women requesting ELCS, reflecting the fact that Turkish women's knowledge about painless childbirth methods is insufficient [5]. Better informing pregnant women about available painless labor methods may reduce the number of women with FOC, the severity of fear in women, and also the number of choosing ELCS section due to fear of labor pain.

In high-income countries, there has been great achievement toward a use of pain-free labor with the nearuniversal utilization of pain relief agents and debates in the point of availability for quality of pain relief services in labor [33]. However, in low-income countries where women are mostly burdened with high pregnancy rates and short inter-pregnancy intervals, pain relief in labor remains a distant reality and so there is a low demand of obstetric analgesia during labor [7] [33] [34]. Similarly high proportion of women from developing countries has poor knowledge regarding the available pain relief methods, their types and advantages which may have lead to low demand of analgesic services than women from developed countries [13]. Increased information access of women during antenatal period was associated with significantly higher use of epidural analgesia with higher satisfaction scores among the developed countries [27]. In a study by Henry, A. et al. antenatal pain management information was accessed by $98 \%$ of women and the most accessed sources were antenatal classes [27]. The decision to use epidural analgesia during labor is influenced not only by the woman's awareness and her background, but also by the local cultural practice in the obstetrician care unit [35]. On the other hand the availability of obstetric analgesic unit in western countries have positive influence towards the attitudes of pregnant women about labor pain relief than which are low in third world countries.

\section{Conclusion}

The awareness and attitudes towards pain during labor and its relieving agents during childbirth among antenatal women are relatively low in developing countries. Lack of knowledge, low level of antenatal discussion and minimum practical exposure regarding available obstetric analgesic services remain a major concern towards acceptance and practice of epidural analgesia among obstetricians, inhibiting the maternal and fetal benefits. The literature shows that obstetrical epidural rates are also similarly low in developing countries than those in western countries like Australia, France, Germany, UK, and USA perhaps because women from developing countries have not yet been made sufficiently aware of the significance of epidural analgesia, and they are more suspicious about its side-effects on the mother and infant's health. The major sources of received information regarding obstetric labor analgesia were from relatives and friends. Therefore, we conclude that practice and quality of epidural analgesia could only be improved by provision of standardized labor analgesia information at an appropriate time in their pregnancy. This may benefit pregnant women by the practice of mutual decisionmaking; which may prevent women from making a difficult choice of CS in order to avoid fear of painful labor.

\section{References}

[1] Lawani, L.O., Eze, J.N., Anozie, O.B., Iyoke, C.A. and Ekem, N.N. (2014) Obstetric Analgesia for Vaginal Birth in Contemporary Obstetrics: A Survey of the Practice of Obstetricians in Nigeria. BMC Pregnancy and Childbirth, $14,1$. http://dx.doi.org/10.1186/1471-2393-14-140

[2] Schrock, S.D. and Harraway-Smith, C. (2012) Labor Analgesia. American Family Physician, 85, 447-454.

[3] El-Wahab, N. and Robinson, N. (2011) Analgesia and Anaesthesia in Labour. Obstetrics, Gynaecology \& Reproductive Medicine, 21, 137-141. http://dx.doi.org/10.1016/j.ogrm.2011.02.006 
[4] Ogboli-Nwasor, E.O. and Adaji, S.E. (2014) Between Pain and Pleasure: Pregnant Women's Knowledge and Preferences for Pain Relief in Labor, a Pilot Study from Zaria, Northern Nigeria. Saudi Journal of Anaesthesia, 8, 20-24. http://dx.doi.org/10.4103/1658-354X.144059

[5] Aksoy, M., Aksoy, A.N., Dostbil, A., Celik, M.G. and Ince, I. (2014) The Relationship between Fear of Childbirth and Women's Knowledge about Painless Childbirth. Obstetrics and Gynecology International, 2014, Article ID: 274303. http://dx.doi.org/10.1155/2014/274303

[6] Ogboli-Nwasor, E., Adaji, S.E., Bature, S.B. and Shittu, O.S. (2011) Pain Relief in Labor: A Survey of Awareness, Attitude, and Practice of Health Care Providers in Zaria, Nigeria. Journal of Pain Research, 4, 227-232.

[7] James, J., Prakash, K. and Ponniah, M. (2012) Awareness and Attitudes towards Labour Pain and Labour Pain Relief of Urban Women Attending a Private Antenatal Clinic in Chennai, India. Indian Journal of Anesthesia, 56, 195-198. http://dx.doi.org/10.4103/0019-5049.96331

[8] Wong, C.A. (2009) Advances in labor Analgesia. International Journal of Women's Health, 1, 139-154. http://dx.doi.org/10.2147/IJWH.S4553

[9] Olayemi, O., Aimakhu, C.O. and Udoh, E.S. (2003) Attitudes of Patients to Obstetric Analgesia at the University College Hospital, Ibadan, Nigeria. Journal of Obstetrics and Gynaecology, 23, 38-40. http://dx.doi.org/10.1080/0144361021000043209

[10] American College of Obstetricians and Gynecologists (2004) ACOG Committee Opinion n. 295: Pain Relief during Labor. Obstetrics \& Gynecology, 104, 213. http://dx.doi.org/10.1097/00006250-200407000-00061

[11] Madden, K.L., Turnbull, D., Cyna, A.M., Adelson, P. and Wilkinson, C. (2013) Pain Relief for Childbirth: The Preferences of Pregnant Women, Midwives and Obstetricians. Women and Birth, 26, 33-40. http://dx.doi.org/10.1016/j.wombi.2011.12.002

[12] Horowitz, E.R., Yogev, Y., Ben-Haroush, A. and Kaplan, B. (2004) Women’s Attitude toward Analgesia during Labor-A Comparison between 1995 and 2001. European Journal of Obstetrics \& Gynecology and Reproductive Biology, 117, 30-32. http://dx.doi.org/10.1016/j.ejogrb.2004.02.033

[13] Shidhaye, R.V., Galande, M., Bangal, V.B., Smita, J. and Shidhaye, U.R. (2012) Awareness and Attitude towards Labour Analgesia of Indian Pregnant Women. Anaesthesia Pain \& Intensive Care, 16, 131-136.

[14] To, W.W. (2007) A Questionnaire Survey on Patients' Attitudes towards Epidural Analgesia in Labour. Hong Kong Medical Journal, 13, 208-215.

[15] Minhas, M.R., Kamal, R., Afshan, G. and Raheel, H. (2005) Knowledge, Attitude and Practice of Parturients Regarding Epidural Analgesia for Labour in a University Hospital in Karachi. Journal of Pakistan Medical Association, 55, 63-66.

[16] Barakzai, A., Haider, G., Yousuf, F., Haider, A. and Muhammad, N. (2010) Awareness of Women Regarding Analgesia during Labour. Journal of Ayub Medical College of Abbottabad, 22, 73-75.

[17] Mugambe, J.M., Nel, M., Hiemstra, L.A. and Steinberg, W.J. (2007) Knowledge of and Attitude towards Pain Relief during Labour of Women Attending the Antenatal Clinic of Cecilia Makiwane Hospital, South Africa. South African Family Practice, 49, 16-16d. http://dx.doi.org/10.1080/20786204.2007.10873535

[18] Vandendriesen, N.M., Lim, W., Paech, M.J. and Michael, C. (1998) Obstetricians’ Knowledge and Attitudes toward Epidural Analgesia in Labour. Anaesthesia and Intensive Care, 26, 563-567.

[19] Kenyon, S., Ullman, R., Mori, R. and Whittle, M. (2008) Care of Healthy Women and Their Babies during Childbirth: Summary of NICE Guidance. Obstetric Anesthesia Digest, 28, 65-66. http://dx.doi.org/10.1097/01.aoa.0000319769.53491.38

[20] Bucklin, B.A., Hawkins, J.L., Anderson, J.R. and Ullrich, F.A. (2005) Obstetric Anesthesia Workforce Survey: Twenty-Year Update. The Journal of the American Society of Anesthesiologists, 103, 645-653.

[21] Richardson, A. and Mmata, C. (2007) National Health Service Maternity Statistics, England: 2005-2006. National Statistics.

[22] Belghiti, E., Bahno, M., Maneglia, R. and Cousin, M.T. (1991) [Evaluation of Epidural Analgesia. Analysis of a Prospective Questionnaire Answered by 100 Women Who Delivered with Epidural Analgesia]. Journal de Gynecologie, Obstetrique et Biologie de la Reproduction, 20, 273-278.

[23] Paech, M.J. and Gurrin, L.C. (1999) A Survey of Parturients Using Epidural Analgesia during Labour. Considerations Relevant to Antenatal Educators. Australian and New Zealand Journal of Obstetrics and Gynaecology, 39, 21-25. http://dx.doi.org/10.1111/j.1479-828X.1999.tb03436.x

[24] Burnstein, R., Buckland, R. and Pickett, J.A. (1999) A Survey of Epidural Analgesia for Labour in the United Kingdom. Anaesthesia, 54, 634-640. http://dx.doi.org/10.1046/j.1365-2044.1999.00894.x

[25] Stamer, U.M., Messerschmidt, A., Wulf, H. and Hoeft, A. (1999) Practice of Epidural Analgesia for Labour Pain: A 
German Survey. European Journal of Anaesthesiology, 16, 308-314. http://dx.doi.org/10.1097/00003643-199905000-00008

[26] Davies, M.W., Harrison, J.C. and Ryan, T.D.R. (1993) Current Practice of Epidural Analgesia during Normal Labour. Anaesthesia, 48, 63-65. http://dx.doi.org/10.1111/j.1365-2044.1993.tb06796.x

[27] Henry, A. and Nand, S.L. (2004) Women’s Antenatal Knowledge and Plans Regarding Intrapartum Pain Management at the Royal Hospital for Women. Australian and New Zealand Journal of Obstetrics and Gynaecology, 44, 314-317. http://dx.doi.org/10.1111/j.1479-828X.2004.00230.x

[28] Lee, B.B., Chen, P.P. and Ngan Kee, W.D. (2003) Status of Obstetric Epidural Analgesia Services in Hong Kong Public Hospitals: Postal Questionnaire Survey. Hong Kong Medical Journal, 9, 407-414.

[29] Chen, P.P., Lee, B.B., Ma, M., Hung, V.Y.S. and Ngan Kee, W.D. (1996) Obstetric Epidural Analgesia in Hong Kong. Hong Kong Medical Journal, 2, 390-395.

[30] Saisto, T. and Halmesmäki, E. (2003) Fear of Childbirth: A Neglected Dilemma. Acta Obstetrician et Gynecologica Scandinavica, 82, 201-208. http://dx.doi.org/10.1034/j.1600-0412.2003.00114.x

[31] Hildingsson, I., Rådestad, I., Rubertsson, C. and Waldenström, U. (2002) Few Women Wish to Be Delivered by Caesarean Section. BJOG: An International Journal of Obstetrics \& Gynaecology, 109, 618-623. http://dx.doi.org/10.1111/j.1471-0528.2002.01393.x

[32] Karlström, A., Rådestad, I., Eriksson, C., Rubertsson, C., Nystedt, A. and Hildingsson, I. (2010) Cesarean Section without Medical Reason, 1997 to 2006: A Swedish Register Study. Birth, 37, 11-20. http://dx.doi.org/10.1111/j.1523-536X.2009.00373.x

[33] Christiaens, W., Verhaeghe, M. and Bracke, P. (2010) Pain Acceptance and Personal Control in Pain Relief in Two Maternity Care Models: A Cross-National Comparison of Belgium and the Netherlands. BMC Health Services Research, 10, 268. http://dx.doi.org/10.1186/1472-6963-10-268

[34] Karuga, R., Nekyon, D. and Mung’ayi, V. (2008) Knowledge, Attitude and Use of Labour Pain Relief Methods among Women Attending Antenatal Clinic in Nairobi. East African Medical Journal, 85, 438-441. http://dx.doi.org/10.4314/eamj.v85i9.117084

[35] Schytt, E. and Waldenström, U. (2010) Epidural Analgesia for Labor Pain: Whose Choice? Acta Obstetrician et Gynecologica Scandinavica, 89, 238-242. http://dx.doi.org/10.3109/00016340903280974

\section{Abbreviations}

American College of Gynecologist and Obstetricians (ACOG)

United Kingdom (UK)

United States of America (USA)

Fear of Childbirth (FOC)

Elective Cesarean Section (ELCS)

Cesarean Section (CS) 